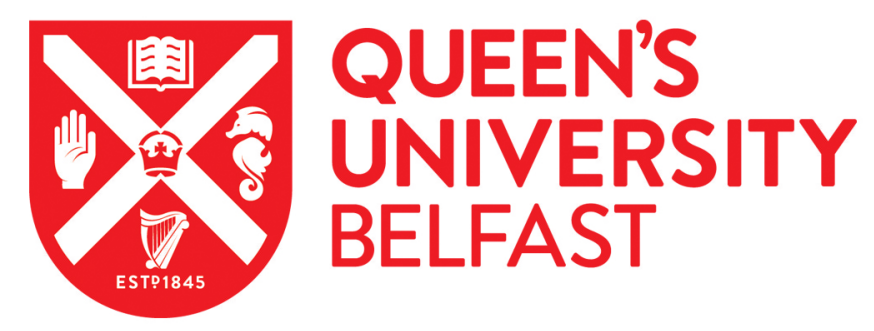

\title{
Process-Induced Degradation of Bioresorbable PDLGA in Bone Tissue Scaffold Production
}

Little, H., Themistou, E., Clarke, S. A., Cunningham, E., \& Buchanan, F. (2018). Process-Induced Degradation of Bioresorbable PDLGA in Bone Tissue Scaffold Production. Journal of Materials Science: Materials in Medicine, 29, [14]. https://doi.org/10.1007/s 10856-018-6035-7

Published in:

Journal of Materials Science: Materials in Medicine

Document Version:

Peer reviewed version

Queen's University Belfast - Research Portal:

Link to publication record in Queen's University Belfast Research Portal

Publisher rights

Copyright 2017 Springer Verlag. This work is made available online in accordance with the publisher's policies. Please refer to any applicable terms of use of the publisher.

\section{General rights}

Copyright for the publications made accessible via the Queen's University Belfast Research Portal is retained by the author(s) and / or other copyright owners and it is a condition of accessing these publications that users recognise and abide by the legal requirements associated with these rights.

Take down policy

The Research Portal is Queen's institutional repository that provides access to Queen's research output. Every effort has been made to ensure that content in the Research Portal does not infringe any person's rights, or applicable UK laws. If you discover content in the Research Portal that you believe breaches copyright or violates any law, please contact openaccess@qub.ac.uk. 


\section{Process-induced degradation of bioresorbable PDLGA in bone tissue scaffold production}

$\underline{\text { H Little }^{1}}$, S A Clarke ${ }^{2}$, E Cunningham ${ }^{1}$, and F Buchanan ${ }^{1 *}$

${ }^{1}$ School of Mechanical and Aerospace Engineering, Queens University Belfast, Ashby Building, Stranmillis Road, BT9 5AH

${ }^{2}$ School of Nursing and Midwifery, Queens University Belfast

*email:f.buchanan@qub.ac.uk

phone: +44 (0)2890974130 


\begin{abstract}
:
Process-induced degradation of clinically relevant resorbable polymers was investigated for two thermal techniques, filament extrusion followed by fused deposition modelling (FDM). The aim was to develop a clear understanding of the relationship between temperature, processing time and resultant process-induced degradation. This acts to address the current knowledge gap in studies involving thermal processing of resorbable polymers. Poly(DL-lactide-co-glycolide) (PDLGA) was chosen for its clinically relevant resorption properties. Furthermore a comparative study of controlled thermal exposure was conducted through compression moulding PDLGA at a selected range of temperatures $\left(150-225^{\circ} \mathrm{C}\right)$ and times $(0.5-20$ minutes). Differential scanning calorimetry (DSC) and gel permeation chromatography (GPC) were used to characterise thermally-induced degradation behaviour. DSC proved insensitive to degradation effects, whereas GPC demonstrated distinct reductions in molecular weight allowing for the quantification of degradation. A near-exponential pattern of degradation was identified. Through the application of statistical chain scission equations, a predictive plot of theoretical degradation was created. Thermal degradation was found to have a significant effect on the molecular weight with a reduction of up to $96 \%$ experienced in the controlled processing study. The proposed empirical model may assist prediction of changes in molecular weight however accuracy limitations are highlighted for twin-screw extrusion, accredited to high shear mixing. The results from this study highlight the process sensitivity of PDLGA and proposes a methodology for quantification and prediction, which contributes to efforts in understanding the influence of manufacture on performance of degradable medical implants.
\end{abstract}

Keywords: Poly(DL-lactide-co-glycolide), Bioresorbable, Processing, Degradation, Additive Manufacturing, Molecular Weight

\title{
1. Introduction
}

Traditionally the majority of orthopaedic implants centre on materials which have little to no resorption, maintaining a long term in vivo presence. Recently there has been a shift from long term solutions to bioresorbable implants for a number of advantageous reasons. Bioresorbable implants prevent long term biocompatibility issues, for example when implants remain in situ for long periods there is potential risk of inflammatory response, infection and loosening which requires removal. In order to avoid this a bioresorbable polymer is ideal [1]. Follow up surgeries to replace or remove implants are eliminated as the device resorbs through natural pathways [2]. Through utilising bioresorbable materials with clinically relevant degradation rates, an implant can satisfy the ideal scaffold characteristic of having a controllable resorption rate to match tissue growth $[3,4]$. However, in order to achieve optimum bone regeneration, material degradation behaviour must be predictable and consistent. Bioresorbable implants are predicted to be an emerging area of growth in the worldwide orthopaedic market which is estimated to reach a value of $\$ 41.2$ billion by 2019 [5]. The success of bioresorbable scaffolds for tissue regeneration in this sector depends on the ability to tailor design and manufacture to achieve suitable mechanical, degradation, and biocompatibility properties [6]. Although the benefits of bioresorbable implants are clear, further knowledge of their degradation behaviour is required to enable their successful application.

The majority of polymers that have been researched for scaffold manufacture have excessively long resorption times, as demonstrated in table 1. Most previous work has mainly involved polycaprolactone (PCL) [7-13], a material which can take over 3 years to fully resorb [14]. Poly(lactic-co-glycolic acid) (PLGA) copolymers are a promising alternative which also have Food and Drug Administration (FDA) approval for clinical use [15]. However, unlike PCL, these materials are inherently difficult to melt process due to their sensitivity to heat and moisture, yet this is one of the most effective ways to form them into various medical devices. PLGA materials have shown promise in the application of bioresorbable sutures [16]. Ulery et al [17] described PLGA as the most investigated bioresorbable polymer for biomedical applications, having been used successfully in tissue engineering scaffolds, demonstrating great cell adhesion and proliferation properties. Poly(DL-lactide-co-glycolide) (PDLGA) (85/15), the focus of this study, is the isomeric form of racemic (d,1) PLGA $[15,18]$, it is a fully amorphous polymer shown to resorb with approximately $90 \%$ mass loss in 10 weeks [19]. Such copolymers of PLA and PGA, can be optimised for intended applications through tailoring compositions. This is evident in the resorption times of 50:50 PDLGA, 75:25 PDLGA, and 85:15 
PDLGA being 1-2 months, 4-5 months, and 5-6 months, respectively [2]. The hydrolysis of PDLGA is faster than other PLGA compositions due to the lack of crystalline regions making this material hydrolytically unstable and sensitive to processing [20]. The rate of resorption of the material is determined by a number of different factors such as copolymer ratio, crystallinity, morphology, porosity, site of implantation and molecular weight [15].

Table 1. Material and degradation times of research conducted in the fused deposition modelling of scaffolds.

\begin{tabular}{|c|c|c|}
\hline Material & Author & Degradation \\
\hline Polycaprolactone (PCL) & $\begin{array}{l}\text { Hutmacher et al }-2001[7] \\
\text { Zein et al }-2002[8] \\
\text { Cao et al }-2003[9] \\
\text { Choong et al }-2004[10] \\
\text { Lam et al }-2007[11] \\
\text { Shor et al }-2007[13] \\
\text { Shor et al }-2009[12]\end{array}$ & $>2$ - 3 Years [14] \\
\hline $\begin{array}{l}\text { Poly(ethylene glycol)- terephthalate- } \\
\text { poly(butylene terephthalate) } \\
\text { (PEGT/PBT) } \\
\text { co-polymer }\end{array}$ & Woodfield et al - 2004 [21] & $\begin{array}{l}>1 \text { Year (dependent on } \\
\text { composition) [22] }\end{array}$ \\
\hline Polypropylene (PP) & Kalita et al - 2003 [23] & Little / No Resorption \\
\hline Polybutylene terephalate (PBT) & Tellis et al - 2008 [24] & $>2$ Years $[14]$ \\
\hline Poly(Lactic Acid) (PLA) & Ciurana et al - 2013 [25] & 2 - 5 Years $[14]$ \\
\hline Poly(DL-lactide-co-glycolide) (PDLGA) & $\begin{array}{l}\text { Kim et al-2012 [26] } \\
\text { Yen et al - } 2008[27]\end{array}$ & 1 - 5 Months [14] \\
\hline
\end{tabular}

It is essential that resorbable orthopaedic devices have predictable resorption. Inadequate control and understanding of melt processing has the potential to significantly affect the in vivo performance of a medical device. Temperature, moisture and shear stresses can all affect molecular weight [28], a key factor influencing degradation behaviour in vivo. Monitoring of the post-processing molecular weight, and understanding the factors affecting molecular degradation during processing is essential to ensure the manufacture of devices with intended mechanical properties and resorption characteristics [29].

Melt processing degradation effects of PLA has been well researched, identifying pronounced degradation [28-30], whereas PDLGA, with its higher sensitivity, has been studied less. Fused deposition modelling (FDM) has demonstrated the ability to manufacture porous structures for tissue engineering [31]. Kim et al [26] and Yen et al [27] have performed FDM studies using PDLGA. Kim et al produced scaffolds through thermally processing filament and subsequent FDM, although in vitro weight loss was recorded, no information was provided on the degradation incurred through thermal processing. Yen et al performed a single thermal FDM process at $170{ }^{\circ} \mathrm{C}$ to create PDLGA scaffolds and noted that through processing, thermal degradation caused a decrease in molecular weight and increase in polydispersity. The average molecular weight $\left(\mathrm{M}_{\mathrm{W}}\right)$ decreased to about $60 \%$ of the original value after the melt-extrusion process [27]. This highlights the importance of monitoring thermal degradation of materials which are more susceptible to resorption. The ability to understand how resorption is affected through processing, storage and implantation is vital to ensure predictability in bone regeneration.

There are still unknown's regarding the degradation of bioresorbable polymers and consequently there is an opportunity to improve the ability to accurately predict and tailor resorption rates. Anderson et al [32] proposes a kinetic model to relate molecular weight changes to bulk hydrolysis degradation mechanisms, allowing the formulation of respective rate equations. It is proposed that degradation may be determined from changes in the number average molecular weight $\left(M_{n}\right)$ by plotting $1 / M_{n}$ and $\ln \left(M_{n}\right)$ vs. time. Use of the Anderson statistical method in literature has also enabled the prediction degradation 
as a result of temperature increases [33], although here samples were contained in a hydrolytic environment. The aim of this work has been to examine degradation induced by melt processing as it has the potential to dramatically influence the molecular weight, an influential attribute of resorption rate. In this article a controlled temperature and time exposure study was utilised to propose a predictive model of the thermal degradation of PDLGA from melt processing that can be applied to processes such as extrusion and FDM. The Anderson kinetic model was arbitrarily applied to directly relate melt processing to polymer degradation.

\section{Materials and Methods}

\subsection{Material}

Medical grade Poly(DL-lactide-co-glycolide) (PDLGA) 85:15 ratio DL-LA/GA (Boehringer Ingelheim Resomer RG 859 SR) in granule form was selected as an appropriate clinically relevant bioresorbable polymer to conduct this study. Non-medical packaging grade Poly (L-lactic acid) (PLLA) (Natureworks 4030D) was used to initially establish baseline extrusion conditions.

\subsection{Filament Fabrication}

Prior to processing, PDLGA granules were dried at $40{ }^{\circ} \mathrm{C}$ in a vacuum oven with 10 mbar pressure for two days before processing. PLLA pellets were cryogenically ground to an extrusion compatible size $(<1 \mathrm{~mm})$ and placed in a drier overnight at $70^{\circ} \mathrm{C}$ before extruding.

Filament was produced using a Haake twin-screw extruder (Thermo Fisher Scientific, Germany). Process parameters were optimised using PLLA to achieve a consistent and FDM compatible diameter whilst minimising degradation. To minimise thermal degradation, temperatures of screw barrel heaters were reduced as much as possible whilst allowing melt flow (values shown in figure 1) and air rings controlling draw down also ensured rapid cooling. To minimise hydrolytic degradation, the hopper was sealed and purged with nitrogen gas. With the line running, PDLGA was processed successive to PLLA through a direct switch of feeding hopper. Only a slight adjustment of draw off speed was required. This allowed for batches as small as $100 \mathrm{~g}$ to be run, avoiding material wastage associated with set up and ensured quick production / minimal exposure to atmosphere. Draw off speed was used to control filament diameter. Circular filament cross-section was maintained through the use of carefully positioned air rings. A screw speed of $300 \mathrm{rpm}$ and draw off speed of $4.6 \mathrm{~m} / \mathrm{min}$ were applied, as shown in figure 1 . Feed rate was increased to achieve a torque value of approximately $60-80 \%$ of the maximum torque to ensure good mixing. Material dwell time was calculated by adding a pigmented granule directly above the start of the screw. A stopwatch was used to record the time until the pigmented coloured material appeared at the die exit. Dwell time measured was 30 seconds.

Once manufactured, filaments were stored in sealed bags and placed in a freezer at $-20^{\circ} \mathrm{C}$ until needed. Prior to use filaments were removed from the freezer and maintained at room temperature overnight before being removed from bags and placed in the desiccator.

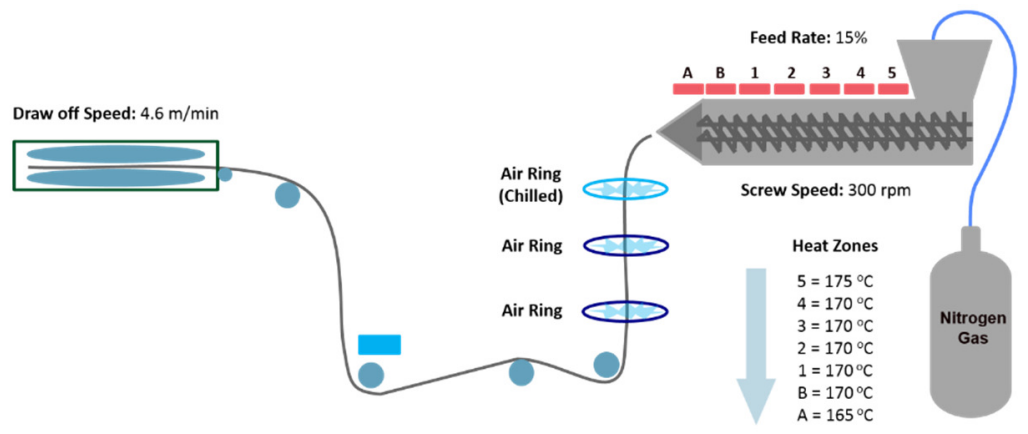

Table 2. FDM parameters.

\begin{tabular}{cc}
\hline Parameter & Value \\
\hline Nozzle Temperature & $180^{\circ} \mathrm{C}$ \\
Bed Temperature & $60^{\circ} \mathrm{C}$ \\
Print Speed (Max) & $22 \mathrm{~mm} / \mathrm{s}$ \\
Nozzle Diameter & $0.4 \mathrm{~mm}$ \\
Filament Diameter & $1.75 \mathrm{~mm}$ \\
Fan Speed & $100 \mathrm{rpm}$ \\
Fan Switch On & Layer 3
\end{tabular}

Fig. 1 Extrusion parameters for the manufacture of PDLGA filament. 


\subsection{Scaffold Fabrication}

A RepRap Tricolour Mendel (RepRapPro, UK) with a nominal $0.3 \mathrm{~mm}$ nozzle was used to manufacture scaffolds from the tailored filaments. A 3-D scaffold structure with open porous geometry was created using SolidWorks 2010. The model STL file was converted into G-Code using open-sourced Sli3er 1.2.9 and processing parameters were also programmed using this software. Prontoface (Printrun 20140406) was used to operate the RepRap. Table 2 details Rep Rap parameters used as defined in Sli3er. The designed scaffold consisted of a cylindrical geometry, $14.6 \mathrm{~mm}$ diameter and $6.2 \mathrm{~mm}$ height, incorporating a $90 \% 90^{\circ}$ laydown pattern with $0.3 \mathrm{~mm}$ layers. To calculate FDM dwell time the time taken for a section of filament to enter, pass through the nozzle and exit was measured. Whilst programed to print a scaffold the dwell time estimated to be 76 seconds, processing a volume of approximately $80 \mathrm{~mm}^{3}$.

\subsection{Controlled Thermal Degradation}

In order to induce thermal degradation in a controlled manner, samples were manufactured using compression moulding. A Colin P220P Platen Press was used to mould sheets (thickness $300 \mu \mathrm{m}$ ) at selected temperature and time exposure periods. Two $300 \mu \mathrm{m}$ spacers were placed at each side of the plate and the material added in the centre. Samples were moulded for 0.5, 2, 5, 10 and 20 minutes at temperatures of $150,175,200$ and $225^{\circ} \mathrm{C}$. A maximum of 10bar pressure was applied to each sample. At the end of the heating phase each sample was crash cooled using cooling platens for 30 seconds at 10 bar pressure. Samples were sealed in bags and placed in a desiccator to be stored for testing.

\subsection{Degradation Analysis}

Differential scanning calorimetry (DSC) (Perkin Elmer DSC6) was used to identify degradation characteristics such as changes in glass transition temperature or indications of crystallization. Samples $(10 \mathrm{mg})$ were sealed in an aluminium pan and scanned in a nitrogen atmosphere. A thermal cycle was conducted on the as supplied (unprocessed) PDLGA. The sample was heated from $25^{\circ} \mathrm{C}$ to $250^{\circ} \mathrm{C}$ at a rate of $10^{\circ} \mathrm{C} / \mathrm{min}$, then held isothermally at this temperature for 15 minutes, before cooling back to $25^{\circ} \mathrm{C}$. This cycle was repeated 10 times to assess progressive changes due to cumulative heat exposure. Thermally processed filament $(10 \mathrm{mg})$ and scaffold samples $(10 \mathrm{mg})$ were scanned without isothermal step for comparison. Samples were heated from $25^{\circ} \mathrm{C}$ to $250^{\circ} \mathrm{C}$ then cooled back to $25^{\circ} \mathrm{C}$ at a rate of $10^{\circ} \mathrm{C} / \mathrm{min}$.

To determine changes in molecular weight after the various processing techniques, gel permeation chromatography (GPC) was used. Experiments were performed using an Agilent Technologies 1260 Infinity GPC with Cirrus GPC software and two PLgel $5 \mu \mathrm{m}$ MIXED-C columns (PS/ DVB) running at $25^{\circ} \mathrm{C}$ and a flow rate of $1.0 \mathrm{~mL} / \mathrm{min}$. Tetrahydrofuran (THF) containing $2.0 \% \mathrm{v} / \mathrm{v}$ triethylamine and $0.05 \% \mathrm{w} / \mathrm{v}$ BHT inhibitor was used as the eluent. Refractive index detectors were operated at $30^{\circ} \mathrm{C}$. The GPC was calibrated using 10 Standard samples in $2 \mathrm{ml}$ PMMA EasiVials with molecular weights equal to $1,010,1,950,6,850,13,900,31,110,68,750,137,800,320,000,569,000$ and 1,048,000 g.mol ${ }^{-}$ ${ }^{1}$. $6 \mu \mathrm{g}$ samples were dissolved overnight in THF $(1 \mathrm{mg} / \mathrm{ml})$ and filtered using a $0.45 \mu \mathrm{m}$ syringe filter. $100 \mu \mathrm{l}$ of the solution was used for analysis. Experiments were performed in batches. Samples to be directly compared were run simultaneously in a single day, this was to avoid potential day to day variance in equipment outputs. The number average molecular weight $\left(\mathrm{M}_{\mathrm{n}}\right)$ for all samples was recorded. Initially GPC was performed on the as-supplied PDLGA, processed filament and printed scaffolds, then compression moulded samples.

\section{Results}

\subsection{Sample Fabrication}

Optimisation of the extrusion process produced consistent FDM compatible filament with a tolerance of $1.75(+0.15 /-0.08) \mathrm{mm}$, compared to commercial filament measured to be $+0.15 /-0.01 \mathrm{~mm}$. Scaffolds were successfully manufactured from the tailored filament as shown in figure 2 . The appearance of the compression moulded samples varied greatly from a clear robust sample produced at the lowest time and temperature exposure (figure 3), to the highest temperature and time exposure producing a darker, embrittled sample (figure 4). 

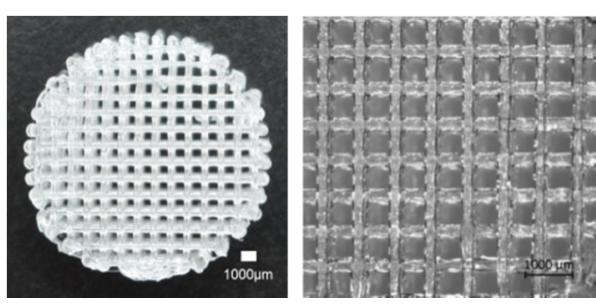

Fig. 2 Medical grade PDLGA FDM scaffold.

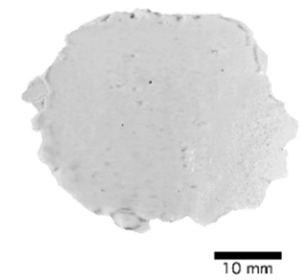

Fig. 3 Sample compression moulded for $0.5 \mathrm{~min}$ at $150^{\circ} \mathrm{C}$.

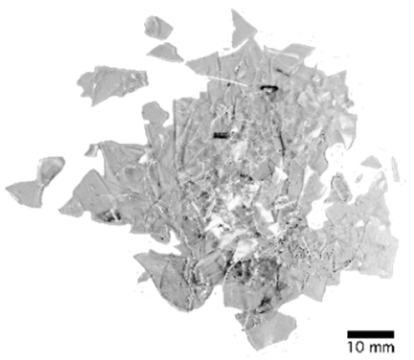

Fig. 4 Sample compression moulded for $20 \mathrm{mins}$ at $225^{\circ} \mathrm{C}$.

\subsection{Degradation Analysis}

Figure 5 shows the DSC thermogram from the as supplied PDLGA, a clear $\mathrm{Tg}$ of $52^{\circ} \mathrm{C}$ can be seen, however no other phase transitions or morphological changes were noted. Known indicators for degradation such as shifts in the Tg and the formation of exothermic crystallisation peaks were not apparent from this material. The same conclusion was drawn from the thermograms for the filament and scaffold (figure 6) with a $\mathrm{Tg}$ of $52^{\circ} \mathrm{C}$, clear amorphous behaviour and no evidence of crystallisation peaks.

\subsection{GPC Analysis}

The number average molecular weight $\left(\mathrm{M}_{\mathrm{n}}\right)$ of the unprocessed material dropped by $36.5 \%$ when processed into filament (Table 3). When this filament was used in a second melt process to manufacture the scaffold, the overall drop with reference to the unprocessed material was $50.8 \%$. Despite the shorter dwell time the largest drop in $\mathrm{M}_{\mathrm{n}}$ is incurred during filament production. These results show a significant change in molecular weight. Molecular weight data for the melt processed materials showed broadened peaks compared to those measured for the suppled material, indicating increases in polydispersity.

\subsection{Controlled Thermal Degradation}

Further investigation into the relationship between thermal exposure and degradation using compression moulding yielded clear patterns of degradation. The number average molecular weight results of each sample have been recorded in figure 7. The as-supplied control for this study had a molecular number of 205,265. These results showed clear temperature and processing time influence on the molecular structure of the polymer, identifying a defined pattern of degradation.

Filament and Scaffold

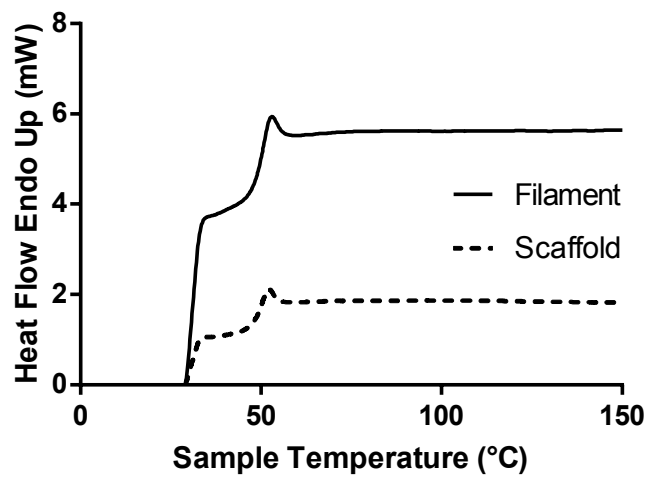

Fig. 5. Cyclic thermogram of as supplied PDLGA.
Fig. 6 Thermogram of processed filament and scaffold. 
Table 3. GPC results of processing stages.

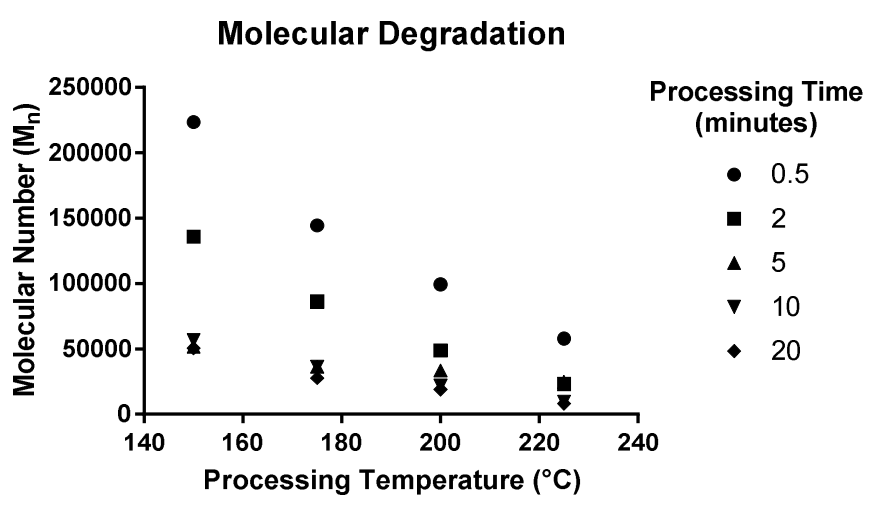

Fig. 7 GPC results of controlled thermal exposure study.

\subsection{Theoretical Prediction of Melt Processing Degradation}

Through measuring thermal degradation over a range of compression moulding times and temperatures GPC data can be gathered and used to plot degradation behaviour trends. Figure 7 demonstrates the constant decline of $\mathrm{M}_{\mathrm{n}}$ over temperature. Through the use Anderson's [32] hydrolysis degradation rate equation (Equation 1) it is possible to devise a predictive model.

$$
\begin{gathered}
1 / M n_{t}=1 / M n_{0}+k_{1} t \\
\text { Where } \mathrm{Mn}_{\mathrm{t}}=\mathrm{Mn} \text { at time, } \mathrm{t} ; \mathrm{Mn}_{0}=\mathrm{Mn} \text { at } \mathrm{t}=0 ; \mathrm{k}_{1}=\text { rate constant; and } \mathrm{t}=\text { time }
\end{gathered}
$$

Although this model is most commonly used for hydrolysis mechanisms of degradation, it was tested here to establish whether it would be appropriate for examining thermal changes which may share the same trends in degradative behaviour. The relationship of $1 / \mathrm{M}_{\mathrm{n}} \mathrm{vs}$ temperature was plotted as shown in figure 8. Rate relationships of each set of data points were obtained through plotting linear best-fit lines in order to obtain the constant rate value $\mathrm{k}$. The coefficient of determination values $\left(\mathrm{r}^{2}\right)$ generated were relatively high for the fit of this model $\left(150^{\circ} \mathrm{C}=0.63,175^{\circ} \mathrm{C}=0.81,200^{\circ} \mathrm{C}=0.86,225^{\circ} \mathrm{C}=0.88\right)$, demonstrating the suitability of use of this hydrolysis equation. The rate constants for each temperature could then be fitted to a predictive kinetic model using the Arrhenius equation (equation 2) to show the rate of the reaction for a given processing temperature and time.

$$
k=A e^{-E a / R T}
$$

Where $\mathrm{k}=$ rate constant; $\mathrm{A}=$ constant; $\mathrm{Ea}=$ activation energy, $\mathrm{J} / \mathrm{mol} ; \mathrm{R}=$ universal gas constant, 8.314 $\mathrm{J} \mathrm{mol}^{-1} \mathrm{~K}^{-1}$; and $\mathrm{T}=$ temperature in Kelvins.

Through taking the natural logarithm of each of the rate constants from figure 8 , a graph can be formed for the extrapolation of results for specific processing times and temperatures (figure 9).

Through the combination of equations 1 and 2, the following predictive equation can be formulated (equation 3). Where $\mathrm{A}=912$ and $\mathrm{Ea}=10806$ as defined by the intercept and rate constant from the Arrhenius Relationship graph (figure 9).

$$
M n_{t}=\frac{1}{\left(1 / M n_{0}\right)+\left(A e^{-E a / R T}\right) t}
$$


Chain Scission Model

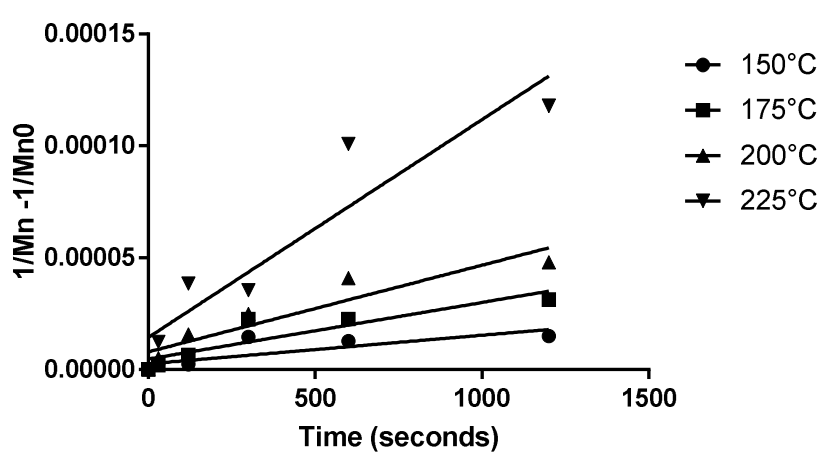

Fig. 8 Chain scission statistical model.
Arrhenius Relationship

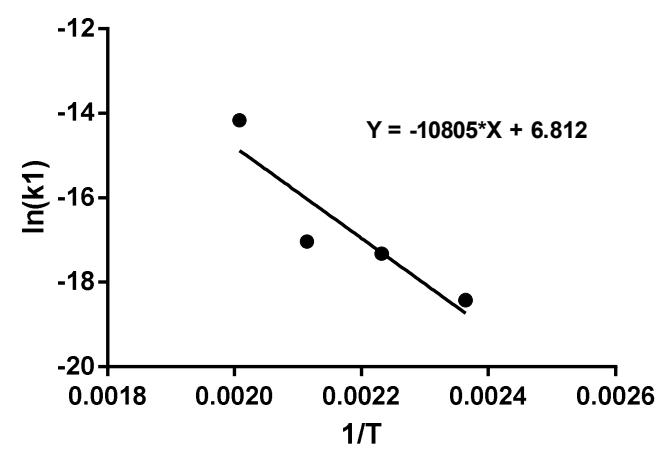

Fig. 9. Arrhenius theoretical prediction model.

\subsection{Validation with Experimental Processing Results}

Using equation 3, it was possible to input processing data from the original extrusion and FDM experiments to check the validation of this model. For extrusion filament samples the average temperature of $170^{\circ} \mathrm{C}$, dwell time of 30 seconds and the molecular weight of the as-supplied material was inputted into equation 3. The predictive model gave a molecular number reading of 146,399 however the GPC measured molecular weight of 103,553, resulting in a model error of $41 \%$. For the FDM scaffold samples a temperature of $180^{\circ} \mathrm{C}$, dwell time of 76 seconds and the molecular weight of the filament as measured by GPC was inputted into equation 3 . This time the predictive model gave a more accurate reading of 78,840; only $1.7 \%$ error off the GPC measured value of 80,224.

\section{Discussion}

\subsection{Thermal Degradation}

Despite evidence of thermally-induced degradation, PDLGA processed without difficulty through extrusion and FDM techniques, forming repeatable designed scaffold architectures. Manufacturing guidelines for processing bioresorbable polymers, as recommended in literature [2,34] have been followed. These include; material drying below its $\mathrm{Tg}$, the addition of nitrogen to a sealed hopper, the rigorous exclusion of moisture, use of the mildest processing conditions possible and storage through double bagging and freezing. Despite both thermal processes reaching temperatures up to $180^{\circ} \mathrm{C}$, there was no discolouration observed, which would have been indicative of extreme degradation. Discoloration and brittleness were however apparent with high temperature and longer dwell time compression moulded samples demonstrating discolouration and loss of mechanical integrity. A 96\% reduction in molecular weight is seen between the most moderate and maximal processing conditions. The reductions between processing temperature changes were distinct, identifying the clear effect of $25^{\circ} \mathrm{C}$ incremental changes. Where molecular weight seemed to increase between processing time of 5 and 10 minutes at $150^{\circ} \mathrm{C}$ and between 2 and 5 minutes at $225^{\circ} \mathrm{C}$, this has been attributed to experimental error. The first processing condition of $0.5 \mathrm{mins}$ at $150^{\circ} \mathrm{C}$ also had a larger molecular weight although values differed by no more than $10 \%$ and can be attributed to experimental error.

For degradation analysis DSC scans were run to a temperature of $250^{\circ} \mathrm{C}$, exceeding compression moulding processing temperatures, however visual signs of degradation seen in the moulded samples were not accounted for with this characterisation technique. It was anticipated that this scan would provide representation of exaggerated repeated thermal processing, and elicit the extreme responses. With no signs of crystallinity and absence of a melting transition phase the amorphous nature of PDLGA was confirmed $[35,36]$. It has been noted that for PLA copolymers changes in Tg are less pronounced than in pure compositions which may explain [37] limited information from this technique. Through GPC, successful quantification of degradation through the measurement of molecular weight was achieved. Results clearly indicated chain scission degradation within the polymer matrix. Confidence 
in the ability to identify and quantify degradation was obtained through this technique. With a reduction of $50.8 \%$ from the as supplied material, the significant effect of using melt processing for the manufacture of bioresorbable PDLGA scaffolds was realised. These results concur with the finding from Yen et al [27] who identified that processing thermal degradation of PDLGA caused a decrease in molecular weight $\left(70,341\right.$ to $\left.33,332 \mathrm{M}_{\mathrm{n}}\right)$ and increase in polydispersity (1.43 to $\left.1.91 \mathrm{M}_{\mathrm{w}} / \mathrm{M}_{\mathrm{n}}\right)$. Although, potentially through the added precautions to minimise degradation and variations in the processes used, a reduced drop in weight average molecular weight $\left(\mathrm{M}_{\mathrm{w}}\right)$ was observed in this study. Yen et al [27] saw a 40\% decrease of molecular weight after the melt-extrusion process performed 170 ${ }^{\circ} \mathrm{C}$, whereas in the twin extrusion of filament for this study the reduction was $33.5 \%$.

\subsection{Accuracy of Prediction Model for Melt Processing Degradation}

Degradation effects were further investigated by a controlled temperature exposure study. Data generated was used to correlate and rationalise results to predict the effect of heat exposure on the bioresorbable material. A comprehensive data set was obtained which covered a wide range of sixteen different processing conditions, examining four processing times at four temperatures. Extreme degradation was demonstrated when samples processed at $250^{\circ} \mathrm{C}$ for over 2 minutes showed discoloration. When processing at the least severe conditions of $150^{\circ} \mathrm{C}$ for 0.5 minutes evidence of original polymer granules was still visible in the sample suggesting insufficient melt fusion. The spread of data generated enabled degradation behaviours to be analysed. Assuming the mechanism of degradation was chain scission, similar to hydrolysis, Anderson's [32] degradation rate equation was applied successfully. The correlation coefficients of each trendline increased as the temperatures increased. Applying the Arrhenius equation, a linear plot was achieved demonstrating appropriate use of this relationship. A high correlation coefficient of 0.836 was achieved. An equation describing melt degradation (equation 3) was then devised and validated. The inaccuracy observed in the validation of the twin screw extruded filament may be explained by the additional element of degradation-inducing high-shear mixing or alternatively error in the accuracy of dwell time and temperature readings. Paakinaho et al [29] and Altpeter et al [28] demonstrated that degradation in extrusion can be attributed to the polymer chains being subjected to high shear stresses as well as high melt temperatures. Such stresses are minimal in both compression moulding processing and FDM. Therefore, the application of this predictive model may only be suitable for those melt processing techniques with minimal shear stress exposure. There is more work required in this area, and potential to apply more advanced modelling techniques to carry out detailed experimental studies furthering understanding [38].

Although this paper has reported the significant effect of melt-processing on molecular weight, which has a direct influence on resorption rate, there are other factors that must be accounted for in order to fully understand a resorbable implant's degradation kinetics. For example Rothen-Weinhold et al [30] reported a lower molecular weight for injection moulding than experienced in extrusion, however in vitro degradation tests suggested the degradation rate was faster for the extruded samples. This was explained as a result of a difference in density and the improved chain orientation (increase of crystallinity) in the injection moulded samples due to the specific process conditions. This demonstrated that, although the melt processing of both techniques strongly influenced molecular degradation properties, the difference in techniques and the morphology of the output also has influence on the resorption performance in vitro. Other factors to be considered include the shape and structure of the implant, and implant location [39]. It is hoped that through better understanding in each of these areas more informative decisions can be made, reducing the trial and error time in device design, and improving confidence in product performance, avoiding property variability and therefore improving clinical success rate.

Future studies should involve degradation experiments simulating in vivo conditions. In such a hydrolytic environment the post-processing molecular weight has been shown to be a significant factor in an implants degradation time [29]. Mass loss degradation as a result of molecular weight reduction from melt processing can then be determined, thus the ability to be able to predict the required molecular weight of the starting as-supplied material for a given application, matching the resorption time required, becomes possible. 


\section{Conclusion}

This study has demonstrated the significant degradation affects attributed to the melt processing of clinically relevant bioresorbable polymers which are particularly susceptible to thermally-induced chain scission. The process of manufacturing a bioresorbable scaffold through extrusion and additive manufacturing techniques has been shown to cause reductions in molecular weight, the largest of which attributed to twin screw extrusion. Despite having a shorter dwell time, the high shear stresses seemed to accelerate molecular degradation. Both processing temperature and time proved influential in molecular weight reduction in compression moulding trials with a $96 \%$ reduction observed between conditions. Compression moulding over a broad range of processing parameters provided data for the creation of a theoretical predictive model. The importance of considering process degradation has been highlighted and a methodology for monitoring and predicting process induced chain scission has been developed. To avail of the benefits of bioresorbables as orthopaedic implants whilst ensuring appropriate performance kinetics it is imperative to utilise this data to inform quality assurance.

\section{Acknowledgements}

The authors would like to acknowledge Smith \& Nephew (York, UK) for supplying materials and the Department for the Economy (NI) for research funding.

\section{References}

1. Gibbons D. Introduction to Medical Implant Materials. In: ASM handbook Volume 23, Materials for medical devices. 2012. p. 3-5.

2. Middleton JC, Tipton AJ. Synthetic biodegradable polymers as orthopedic devices. Biomaterials. 2000;21(23):2335-46.

3. Hutmacher DW. Scaffolds in tissue engineering bone and cartilage. Biomaterials. 2000;21:2529-43.

4. Hutmacher DW. Scaffold design and fabrication technologies for engineering tissues — state of the art and future perspectives. J Biomater Sci Polym Ed. 2001;12(1):107-24.

5. Transparency Market Research. Orthopedic Devices Market (Hip, Knee, Spine, Shoulder, Elbow, Foot and Ankle, Craniomaxillofacial and Other Extremities) - Global Industry Analysis, Size, Share, Growth, Trends and Forecast, 2013 - 2019. 2014.

6. Sabir MI, Xu X, Li L. A review on biodegradable polymeric materials for bone tissue engineering applications. J Mater Sci. 2009;44(21):5713-24.

7. Hutmacher DW, Schantz T, Zein I, Ng KW, Teoh SH, Tan KC. Mechanical properties and cell cultural response of polycaprolactone scaffolds designed and fabricated via fused deposition modeling. J Biomed Mater Res. 2001;55(2):203-16.

8. Zein I, Hutmacher DW, Tan KC, Teoh SH. Fused deposition modeling of novel scaffold architectures for tissue engineering applications. Biomaterials . 2002;23(4):1169-85.

9. Cao T, Ho K-H, Teoh S-H. Scaffold design and in vitro study of osteochondral coculture in a three-dimensional porous polycaprolactone scaffold fabricated by fused deposition modeling. Tissue Eng. 2003;9 Suppl 1:S103-12.

10. Choong C, Triffitt JT, Cui ZF. Polycaprolactone Scaffolds for Bone Tissue Engineering Effects of a Calcium Phosphate Coating Layer on. Food Bioprod Process. 2004;82:117-25.

11. Lam CXF, Teoh SH, Hutmacher DW. Comparison of the degradation of polycaprolactone and polycaprolactone-(ß-tricalcium phosphate) scaffolds in alkaline medium. Polym Int. 2007;56(6):718-28.

12. Shor L, Güçeri S, Chang R, Gordon J, Kang Q, Hartsock L, et al. Precision extruding deposition (PED) fabrication of polycaprolactone (PCL) scaffolds for bone tissue engineering. Biofabrication. 2009;1(1):15003. 
13. Shor L, Güçeri S, Wen X, Gandhi M, Sun W. Fabrication of three-dimensional polycaprolactone/hydroxyapatite tissue scaffolds and osteoblast-scaffold interactions in vitro. Biomaterials. 2007;28(35):5291-7.

14. Nair LS, Laurencin CT. Biodegradable polymers as biomaterials. Prog Polym Sci. 2007;32(89):762-98.

15. Gunatillake P a., Adhikari R, Gadegaard N. Biodegradable synthetic polymers for tissue engineering. Eur Cells Mater. 2003;5:1-16.

16. Nair LS, Laurencin CT. Biodegradable polymers as biomaterials. Prog Polym Sci. 2007;32(89):762-98.

17. Ulery BD, Nair LS, Laurencin CT. Biomedical Applications of Biodegradable Polymers. $J$ Polym Sci B Polym Phys. 201;49(12):832-64.

18. Makadia HK, Siegel SJ. Poly Lactic-co-Glycolic Acid (PLGA) as Biodegradable Controlled Drug Delivery Carrier. Polymers (Basel). 2011;3:1377-97.

19. Cotton NJ, Egan MJ, Brunelle JE. Composites of poly(DL-lactide-co-glycolide) and calcium carbonate: In vitro evaluation for use in orthopedic applications. J Biomed Mater Res - Part A. 2008;85(1):195-205.

20. Rezwan K, Chen QZ, Blaker JJ, Boccaccini AR. Biodegradable and bioactive porous polymer/inorganic composite scaffolds for bone tissue engineering. Biomaterials. 2006;27(18):3413-31.

21. Woodfield TBF, Malda J, De Wijn J, Péters F, Riesle J, Van Blitterswijk C a. Design of porous scaffolds for cartilage tissue engineering using a three-dimensional fiber-deposition technique. Biomaterials. 2004;25(18):4149-61.

22. Lamme EN, Druecke D, Pieper J, May PS, Kaim P, Jacobsen F, et al. Long-term evaluation of porous PEGT/PBT implants for soft tissue augmentation. J Biomater Appl. 2008;22:309-35.

23. Kalita SJ, Bose S, Hosick HL, Bandyopadhyay A. Development of controlled porosity polymer-ceramic composite scaffolds via fused deposition modeling. Mater Sci Eng C. 2003;23(5):611-20.

24. Tellis BC, Szivek J a., Bliss CL, Margolis DS, Vaidyanathan RK, Calvert P. Trabecular scaffolds created using micro CT guided fused deposition modeling. Mater Sci Eng C. 2008;28(1):171-8.

25. de Ciurana J, Serenóa L, Vallès È. Selecting Process Parameters in RepRap Additive Manufacturing System for PLA Scaffolds Manufacture. Procedia CIRP. 2013;5:152-7.

26. Kim J, McBride S, Tellis B, Alvarez-Urena P, Song Y-H, Dean DD, et al. Rapid-prototyped PLGA/ $\beta$-TCP/hydroxyapatite nanocomposite scaffolds in a rabbit femoral defect model. Biofabrication. 2012;4(2):25003.

27. Yen HJ, Tseng CS, Hsu SH, Tsai CL. Evaluation of chondrocyte growth in the highly porous scaffolds made by fused deposition manufacturing (FDM) filled with type II collagen. Biomed Microdevices. 2009;11(3):615-24.

28. Altpeter H, Bevis MJ, Grijpma DW, Feijen J. Non-conventional injection molding of poly(lactide) and poly(epsilon-caprolactone) intended for orthopedic applications. J Mater Sci Mater Med. 2004;15(2):175-84.

29. Paakinaho K, Ellä V, Syrjälä S, Kellomäki M. Melt spinning of poly(1/d)lactide 96/4: Effects of molecular weight and melt processing on hydrolytic degradation. Polym Degrad Stab. 2009;94(3):438-42.

30. Rothen-Weinhold A, Besseghir K, Vuaridel E, Sublet E, Oudry N, Kubel F, et al. Injectionmolding versus extrusion as manufacturing technique for the preparation of biodegradable implants. Eur J Pharm Biopharm. 1999;48(2):113-21.

31. Yeong W-Y, Chua C-K, Leong K-F, Chandrasekaran M. Rapid prototyping in tissue 
engineering: challenges and potential. Trends Biotechnol [Internet]. 2004 Dec [cited 2014 Jul 11];22(12):643-52.

32. Anderson J. M. Perspectives on the in vivo responses of biodegradable polymers. Biomedical Applications of Synthetic Biodegradable Polymers. Hollinger JO, editor. CRC Press, Boca Raton, FL, USA; 1995. p. 223-33.

33. Weir NA, Buchanan FJ, Orr JF, Farrar DF DG. Degradation of poly-L- lactide. Part 2: increased temperature accelerated degradation. Proc IME H J Eng Med. 2004;218(5):321-30.

34. Burg KJL, Orr DE. An overview of bioresorbable materials. Degradation Rate of Bioresorbable Materials. Buchanan F, editor. Woodhead Publishing; 2008. p. 3-18. (Woodhead Publishing Series in Biomaterials).

35. Petisco S, Larrañaga A, Sarasua JR. Effects of thermo-mechanical treatments on mechanical properties of lactide derived (co)polymers. Soc Plast Eng - EUROTECH 2013. 2013;477-82.

36. D 'avila C, Erbetta C, Alves RJ, Resende JM, Fernando De Souza Freitas R, Geraldo De Sousa R. Synthesis and Characterization of Poly(D,L-Lactide-co-Glycolide) Copolymer. J Biomater Nanobiotechnol. 2012;3:208-25.

37. Ragaert K, Dekeyse A, Cardon L, Degrieck J. Quantification of Thermal Material Degradation During the Processing of Biomedical Thermoplastics. J Appl Polym Sci. 2011;120:2872-2880.

38. Farrar D. Modelling of the degradation process for bioresorbable polymers. Degradation Rate of Bioresorbable Materials. Buchanan F, editor. Woodhead Publishing; 2008. p. 3-18. (Woodhead Publishing Series in Biomaterials).

39. Athanasiou KA, Agrawal CM, Barber FA, Burkhart SS. Orthopaedic applications for PLAPGA biodegradable polymers. Arthroscopy. 1998;14(7):726-37. 